\title{
Inhibition of Kupffer cell functions modulates arsenic intoxication in Wistar rats
}

\author{
Oluyomi S. Adeyemi ${ }^{1}$, Ekong Meyakno ${ }^{1}$ and Musbau A. Akanji ${ }^{2}$ \\ ${ }^{1}$ Medicinal Biochemistry and Toxicology Laboratory, Department of Biological Sciences, Landmark University, Omu-Aran, \\ Nigeria \\ ${ }^{2}$ Department of Biochemistry, University of Ilorin, Nigeria
}

\begin{abstract}
Study determined the influence of the inhibition of Kupffer cell functions by $\mathrm{GdCl}_{3}$ in arsenic intoxication. Twenty-four Wistar rats weighing between 150 and $160 \mathrm{~g}$ were randomly assigned into four groups. Group 1 received sodium arsenite $(1.5 \mathrm{mg} / \mathrm{kg}$ b.w.) once a day, Group 2 received $\mathrm{GdCl}_{3}(2 \mathrm{mg} / \mathrm{kg}$ b.w.) once, 24 hours before commencing the arsenite $(1.5 \mathrm{mg} / \mathrm{kg}$ b.w.) treatment. Group 3 received $\mathrm{GdCl}_{3}(2 \mathrm{mg} / \mathrm{kg}$ b.w.) once and subsequently given distilled water. Group 4 received distilled water only. The treatments were daily by oral gavage and lasted for 28 days. Animals were euthanized 24 hours after the last treatment. Arsenic exposure elevated the activities of rat plasma AST, ALT, ALP and $\gamma$-GT, indicative of liver injury. Arsenic exposure in rat lowered GSH concentration but potentiated inflammation and oxidative stress evidenced in the raised levels of MPO, NO and MDA. Rats with arsenic exposure were predisposed to atherosclerosis, lowering the HDL-C but elevated the LDL-C concentration. The histopathological assessment showed degenerating cellular lesion caused by arsenic. However, the inhibition of Kupffer cell functions by $\mathrm{GdCl}_{3}$ suppressed arsenic intoxication improving the liver function indices, oxidative stress status, lipid profile, neutrophilic inflammation and ultimately restored the cellular architecture. Data suggest that specific inhibition of Kupffer cells by $\mathrm{GdCl}_{3}$ protected against arsenic intoxication.
\end{abstract}

Key words: Arsenic - Atherosclerosis - Hepatotoxicity - Kupffer cells - Metals

Abbreviations: AI, atherogenic index; ALP, alkaline phosphatase; ALT, alanine transaminase; AST, aspartate transaminase; $\mathrm{CHOL}$, total cholesterol; $\mathrm{GdCl}_{3}$, gadolinium chloride; $\mathrm{GSH}$, reduced glutathione; $\gamma$-GT, $\gamma$ glutamyl transferase; HDL-C, high density lipoprotein cholesterol; LDL-C, low density lipoprotein cholesterol; MDA, malondialdehyde; MPO, myeloperoxidase; NO, nitric oxide.

\section{Introduction}

Arsenic, as trivalent $\left(\mathrm{As}^{3+}\right)$ and pentavalent salt $\left(\mathrm{As}^{5+}\right)$, is released into the environment via agricultural, industrial and medical applications (Aliyu et al. 2012). Arsenic is a toxic metalloid and a common contaminant of drinking water. Arsenical exposure through drinking water is common and occurs in many areas of the world (Morakinyo et al. 2010).

Correspondence to: Oluyomi S. Adeyemi, Medicinal Biochemistry and Toxicology Laboratory, Department of Biological Sciences, Landmark University, Omu-Aran 370102, Nigeria

E-mail: yomibowa@yahoo.com
Consumption of arsenic-contaminated water increases risk of cardiovascular disease, lung disease, hepatic disease, and cancer in millions of people worldwide (Okoji et al. 2002; Straub et al. 2008; Das et al. 2012; Kumar et al. 2014). Arsenic-contaminated drinking water is associated with several adverse health effects in many developing areas around the world, including China, India, Mexico, and Bangladesh (Aliyu et al., 2012; Das et al. 2012).

Arsenite intoxication limits ATP production (Hughes et al. 2011), while potentiating oxidative stress which readily leads to cellular dysfunction (Rana et al. 2011). While the mechanism of arsenic toxicity remains limited, current treatment and preventive measures for arsenic intoxica- 
tion are still elusive (Chowdhury et al. 2006). Therefore, identifying the cellular factors that contribute to modulate the liver response to arsenicals is central to understanding their toxicology. We reasoned that, identifying cellular factors involved in liver response to arsenic intoxication would further aid our understanding of its mode of toxic action as well as provide opportunity for the development of newer treatment strategy.

Kupffer cells are macrophage native to the liver and mediate hepatic response to chemical assault (Roberts et al. 2007). Generally, Kupffer cells play an important role in the normal physiology and homeostasis of the liver as well as participate in the acute and chronic responses of the liver to toxic compounds and have been shown to modulate hepatic injury (Yee et al. 2000; Roberts et al. 2007). Several studies have demonstrated the central role played by Kupffer cells in liver responses to the toxic action of several drugs (Yee et al. 2000; Ju et al. 2002; Ito et al. 2003; Prins et al. 2004; Yao et al. 2004; Kresse et al. 2005). Meanwhile, it has been demonstrated that pretreatment of mice with $\mathrm{GdCl}_{3}$, a specific inhibitor of Kupffer cells, offered protection against liver injury (Jorgensen et al. 2001). Further, in a separate investigation, Ding et al. (2003) showed that the intraperitoneal administration of $\mathrm{GdCl}_{3}$ to mice at doses between 10-20 $\mathrm{mg} / \mathrm{kg}$ caused apoptosis of Kupffer cells and blocked the Kupffer cell effector function without necessarily damaging the liver. Currently, there is no empirical data on how Kupffer cells affect arsenic toxicity. Therefore, determining the role Kupffer cells play in arsenical intoxication may be essential to understanding the mode of the toxic action. To this end, this study evaluated the influence of the inhibition of Kupffer cell functions by $\mathrm{GdCl}_{3}$ in experimental arsenic intoxication.

\section{Materials and Methods}

\section{Chemicals reagents}

All chemicals and reagents used were of analytical grade. Sodium arsenite $\left(\mathrm{NaAsO}_{2}\right)$ and $\mathrm{GdCl}_{3}$ were products of Sigma Chemicals (St. Louis, MO, USA). Reagent assay kits for aspartate aminotransferase (AST), alanine aminotransferase (ALT), $\gamma$-glutamyl transferase $(\gamma$-GT), total cholesterol (CHOL), high-density lipoprotein (HDL), bilirubin, and albumin were products of Randox Laboratories (Crumlin, UK).

\section{Experimental animals}

Twenty-four male Wistar rats weighing between 150 and $160 \mathrm{~g}$ were purchased from the experimental animal farm at the Landmark University, Nigeria. The rats were housed in plastic cages and kept in a well-ventilated room, with alternate light and dark cycle ( $12 \mathrm{~h}$ each). The animals were acclimatized for 14 days before the treatment commenced. The animals were fed standard rat chow and clean water ad libitum. Handling of animals was in accordance with relevant institutional and ethical guidelines as approved for scientific study.

\section{Experimental design}

The Wistar rats were randomly assigned into four groups. Details of groupings and treatments are as follows:

Group 1: Administered with arsenite $\left(\mathrm{NaAsO}_{2}\right)$ at $1.5 \mathrm{mg} /$ $\mathrm{kg}$ body weight.

Group 2: Administered once with $\mathrm{GdCl}_{3}$ at $2 \mathrm{mg} / \mathrm{kg}$ b.w., $24 \mathrm{~h}$ before starting treatment with arsenite $\left(\mathrm{NaAsO}_{2}\right)$ at $1.5 \mathrm{mg} / \mathrm{kg}$ b.w.

Group 3: Administered once with $\mathrm{GdCl}_{3}$ at $2 \mathrm{mg} / \mathrm{kg}$ b.w. and subsequently received distilled water.

Group 4: Administered with distilled water and served as sham control.

The arsenite dose was premised on report by Zaki et al (2011). The arsenite dose $1.5 \mathrm{mg} / \mathrm{kg}$ body weight/day falls within the range of $\mathrm{LD}_{50}$ of a $70 \mathrm{~kg}$ b.w. human $(1-4 \mathrm{mg} /$ $\mathrm{kg}$ ) and lesser than $1 / 25$ of $\mathrm{LD}_{50}$ of rats $(40 \mathrm{mg} / \mathrm{kg})$. The treatments were daily by oral gavage and lasted for 28 days. Handling of animals was as approved by the Landmark University Research Ethics Committee and consistent with relevant guidelines on the care and use of laboratory animals (National Research Council 2011).

\section{Necroscopy}

Rats were sacrificed under mild chloroform anesthesia $24 \mathrm{~h}$ after the last treatments. Blood samples were collected into EDTA bottles, centrifuged at $5000 \times g$ for 5 minutes in a refrigerated centrifuge (Anke TDL-5000B, Shanghai, China) to obtain the plasma used for the biochemical determinations. The liver from each animal was excised into iced isotonic solution ( $\mathrm{pH}$ 7.4) and weighed immediately. A fifth of the liver sample was homogenized in iced $0.25 \mathrm{M}$ sucrose solution $(1: 5, \mathrm{w} / \mathrm{v})$. The liver homogenates were used for the biochemical determinations. The remaining part of the liver was fixed in 10\% buffered neutral formalin (BNF) and used for histopathology examinations.

\section{Biochemical assays}

The biochemical parameters were determined in rat plasma using a UV/Vis spectrophotometer (Jenway, Staffordshire, United Kingdom) where applicable. The concentration of rat plasma total protein (TP), aspartate aminotransferase (AST, EC: 2.6.1.1), alanine aminotransferase (ALT, EC 
2.6.1.2), alkaline phosphatase (ALP, EC: 3.1.3.1), $\gamma$-glutamyl transferase ( $\gamma$-GT, EC 2.3.2.2), bilirubin, albumin, lipid profile including total cholesterol (CHOL), high-density lipoprotein-cholesterol (HDL-C) were determined using Randox assay kits (Crumlin, UK). The low-density lipoprotein cholesterol (LDL-C) was estimated according to the Friedewald formula (Warnick et al. 1990). Total protein was determined using the Lowry's method (Lowry et al. 1951). Reduced glutathione level (GSH) was determined by the procedure described by Ellman (1959) and Akanji et al (2009). Malondialdehyde (MDA) was determined using the method described by Niehaus and Samuelson (1968). The concentration of nitric oxide as nitrite/nitrate level was determined using the Greiss method according to method described by Ekanem et al. (2009). The myeloperoxidase (MPO - EC 1.11.2.2) activity was determined as previously described (Adeyemi and Sulaiman 2014), according to the method by Eiserich et al. (1998).

\section{Histopathological examination}

The rat liver was fixed in $10 \%$ buffered neutral formalin immediately following excision from animals. Fixed tissues were subsequently processed for histopathological examinations as previously described (Adeyemi and Sulaiman 2012). Capture and scoring for morphological changes were done by a pathologist blind to the treatments, at the University of Ilorin Teaching Hospital, Ilorin, Nigeria. The photomicrographs were captured at $\times 100$ using the software "Presto! Image Folio package".

\section{Data analysis}

Data were analyzed using the one-way ANOVA (GraphPad Software Inc., San Diego, CA) and presented as the mean \pm standard error of mean (SEM). Differences among the group means were determined by the Tukey's test. Mean values at $p<0.05$ were considered to be significant.

\section{Results}

Arsenite exposure had no appreciable effect on rat average weights when compared to the other treatment groups (Fig. 1). However, the rat liver weights as well as the liverto-body weight ratio were significantly reduced by arsenite.

Furthermore, oral exposure of rats to arsenite did not alter the concentration of plasma total protein. In contrast, the rat plasma albumin concentration was appreciably decreased relative to the other treatment groups (Fig. 2). Arsenic treatment in rats led to a significant elevation of plasma bilirubin concentration relative to the other treatments.
In comparison to the other treatment groups, the oral exposure of rats to arsenic for 28 days suggest impairment to liver function as evidenced by increased $(p<0.05)$ activities of plasma AST, ALT, ALP and $\gamma$-GT (Fig. 3). Also, arsenic exposure elevated rat plasma and hepatic MDA concentration but depleted the GSH levels when compared to the other treatments (Fig. 4). Likewise, arsenic exposure increased the levels of MPO and NO relative to the other treatment groups (Fig. 5). The rat plasma lipid profile was not spared, as arsenic exposure elevated the concentration of CHOL, LDL-C but reduced the HDL-Clevel, thereby increasing the atherogenic index (AI). The negative alterations of plasma lipid profile by arsenic were absent in the other treatment groups (Fig. 6).

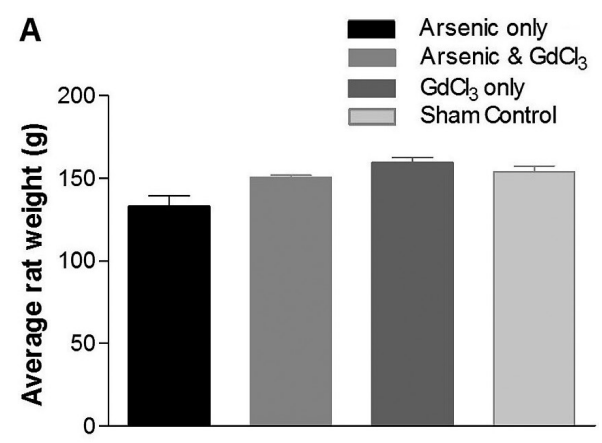

B

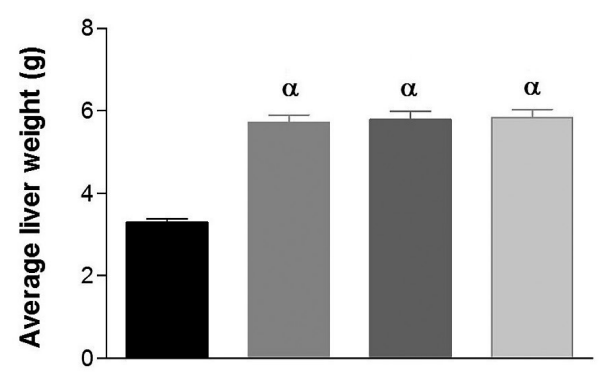

C

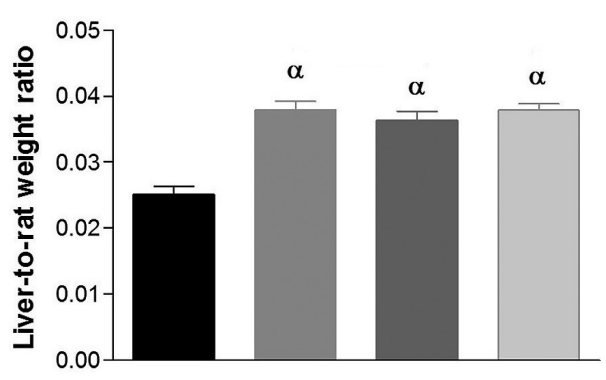

Figure 1. Effect of oral exposure of rats to arsenite and/or gadolinium chloride $\left(\mathrm{GdCl}_{3}\right)$ on average rat weight $(\mathbf{A})$, rat liver weight $(\mathbf{B})$ and liver-to-body weight ratio (C). Data are presented as mean value \pm standard error of mean (SEM), $n=6 . \alpha$ is significant at $p<$ 0.001 relative to arsenic only. 
The histopathological assessment of rat liver sections showed inimical cellular lesions including congestion and inflammation caused by arsenic exposure (Fig. 7). However, pre-treating rats with $\mathrm{GdCl}_{3}$ before daily exposure to arsenic improved the cellular alterations. In the other groups that received $\mathrm{GdCl}_{3}$ alone and/or distilled water only, the liver cellular architecture was intact.

\section{Discussion}

Arsenic is a toxic metalloid (Aliyu et al. 2012; Das et al. 2012). However, the knowledge of the mechanism of arsenic toxicity
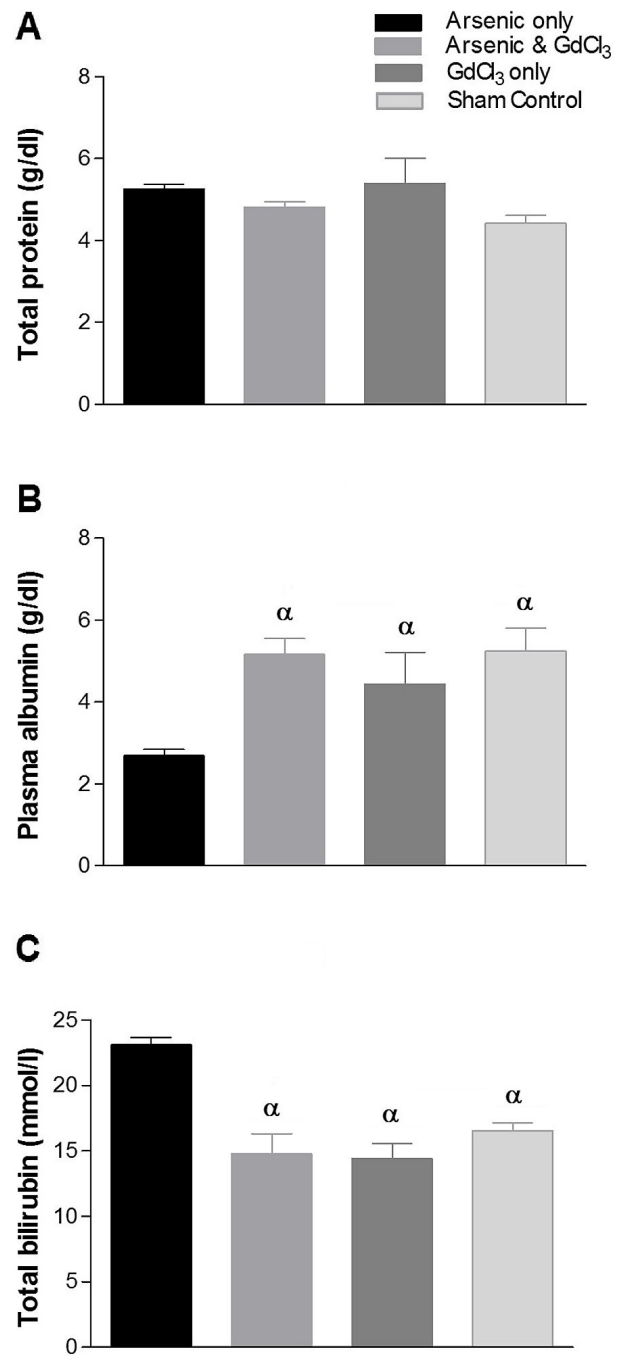

Figure 2. Effect of oral exposure of rats to arsenite and/or gadolinium chloride $\left(\mathrm{GdCl}_{3}\right)$ on rat plasma protein concentration $(\mathbf{A})$, rat plasma albumin (B) and rat plasma bilirubin (C). Data are presented as mean value \pm SEM, $n=6$. $\alpha$ is significant at $p<0.001$ relative to arsenic only. remains limited. We reasoned that, identifying the cellular factors that contribute to modulate the response to arsenical toxicity would provide for a better understanding of the mode of toxicity. Kupffer cells have been shown to modulate hepatic injury as well as play key role in the mediation of

A
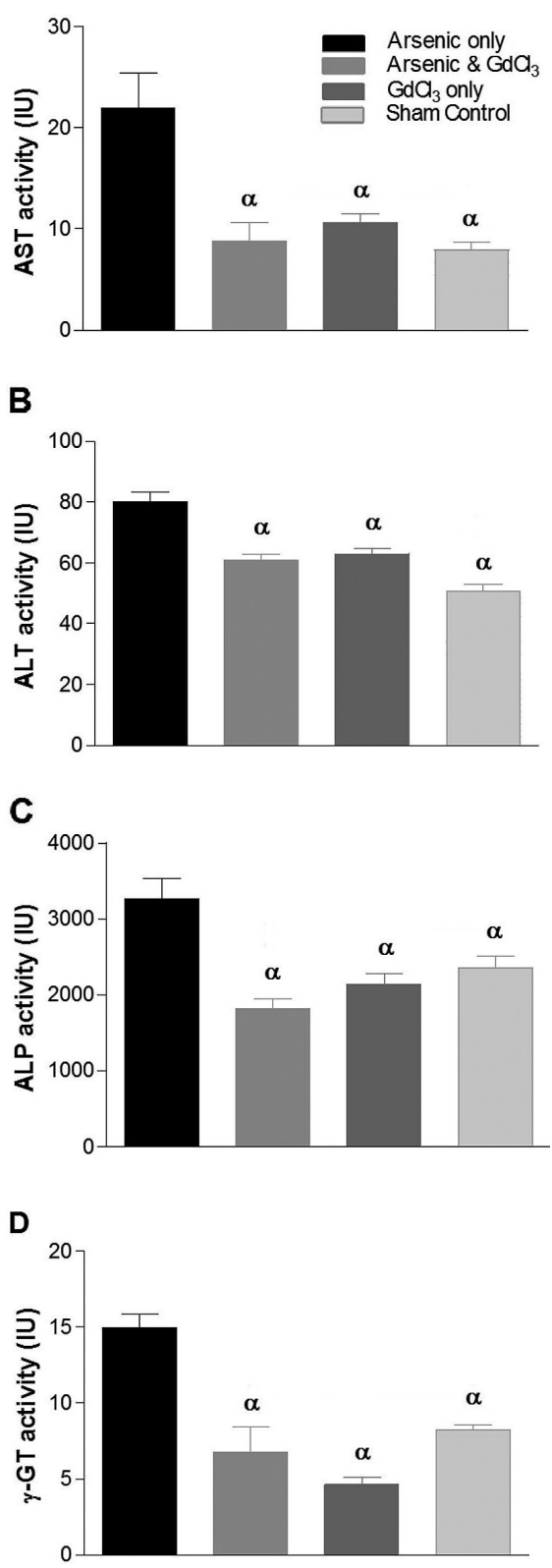

Figure 3. Effect of oral exposure of rats to arsenite and/or gadolinium chloride $\left(\mathrm{GdCl}_{3}\right)$ on rat plasma aspartate transaminase (AST) activity (A), rat plasma alanine transaminase (ALT) activity (B), rat plasma alkaline phosphatase (ALP) activity (C) and rat plasma $\gamma$-glutamyl transferase $(\gamma$-GT) activity $(\mathbf{D})$. Data are presented as mean value $\pm \operatorname{SEM}, n=6$. $\alpha$ is significant at $p<0.001$ relative to arsenic only. 
metal toxicity (Roberts et al. 2007). Therefore, identifying the role Kupffer cells play in arsenic intoxication would aid understanding the mode of toxicity. The present study by
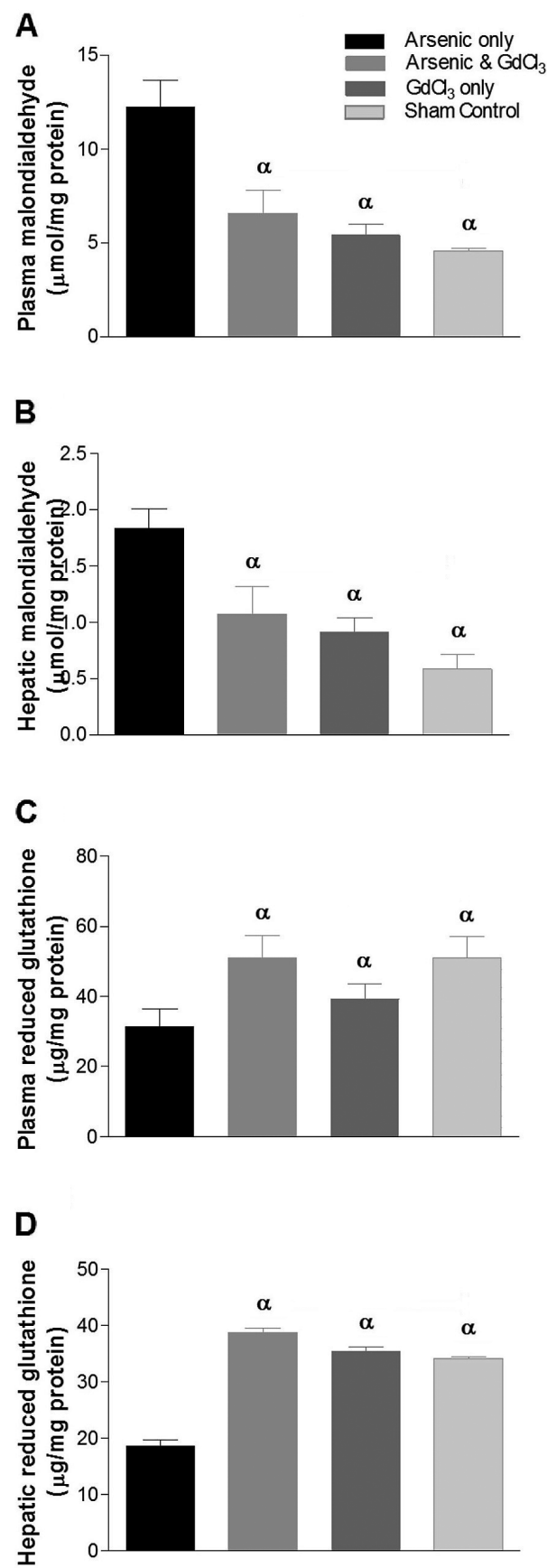

Figure 4. Effect of oral exposure of rats to arsenite and/or gadolinium chloride $\left(\mathrm{GdCl}_{3}\right)$ on rat plasma malondialdehyde (MDA) concentration (A), rat hepatic malondialdehyde (MDA) concentration (B), rat plasma reduced glutathione (GSH) concentration (C) and rat hepatic reduced glutathione (GSH) concentration (D). Data are presented as mean value $\pm \operatorname{SEM}, n=6$. $\alpha$ is significant at $p<$ 0.001 relative to arsenic only. using aimed to determine how Kupffer cells affect arsenic intoxication by using $\mathrm{GdCl}_{3}$ to inhibit Kupffer cell functions.

Arsenic exposure in rats significantly reduced the rat liver weight as well as the liver-to-body weight ratio. This may indicate ensuing adverse effect by arsenite as studies have associated changes to body or organ weights with chemical or drug intoxication (Adeyemi and Orekoya 2014; Sulaiman et al. 2015). This is consistent with other studies have demonstrated arsenic-induced changes to rat body or organ weights (Aliyu et al. 2012; Chandraayagam et al. 2013).

Further evidence for arsenite-induced liver injury is reflected by the negative alteration of the activities of rat plasma AST, ALT, ALP and $\gamma$-GT. Increased liver function indices are evidence of liver damage (Adeyemi and Akanji 2011a; Adeyemi et al. 2012). The arsenic-induced elevation of liver function indices is consistent with the potential to cause liver damage (Gbadegesin and Odunola 2010; Das et al. 2012; Kumar et al. 2014). More so, the arsenite-induced negative alteration of the plasma albumin and bilirubin concentration suggests liver injury or reduced functioning capacity.

The arsenic exposure also caused oxidative stress by potentiating lipid peroxidation while depleting the GSH concentrations. GSH plays key role protecting against metal toxicity (Swaran et al. 2005; Mishra et al. 2008) and its deple-
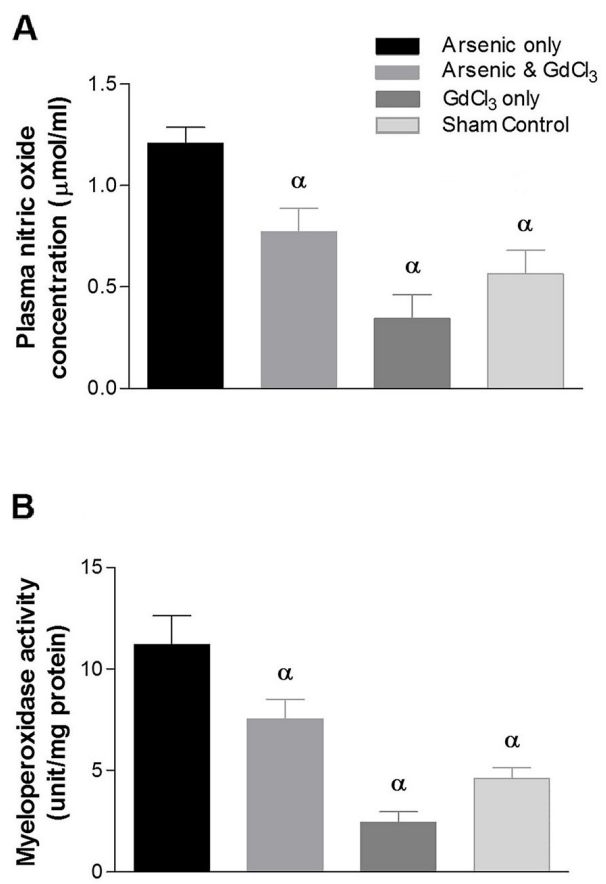

Figure 5. Effect of oral exposure of rats to arsenite and/or gadolinium chloride $\left(\mathrm{GdCl}_{3}\right)$ on rat plasma nitric oxide $(\mathrm{NO})$ concentration measured as nitrate/nitrite level (A) and rat plasma myeloperoxidase (MPO) activity (B). Data are presented as mean value \pm SEM, $n=6$. $\alpha$ is significant at $p<0.001$ relative to arsenic only. 
tion may signal oxidative stress (Akanji et al. 2009). In the present study, the use of GSH to detoxify arsenite may have led to the depletion and ensuing oxidative stress observed.
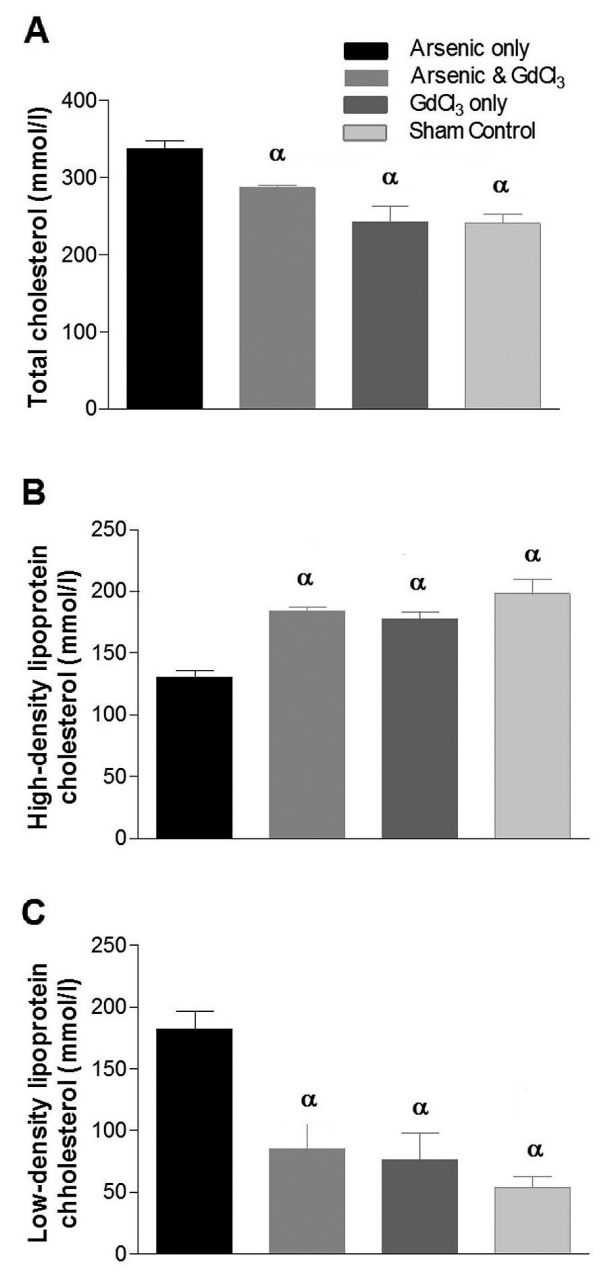

D

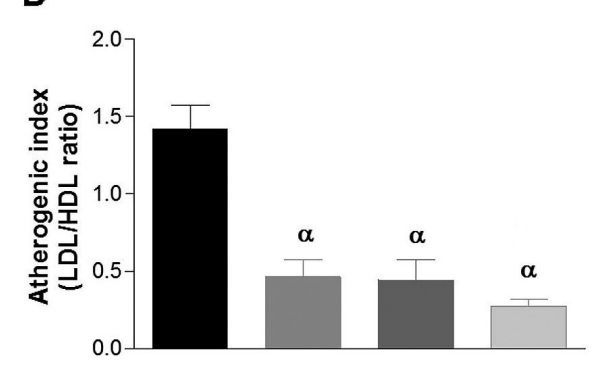

Figure 6. Effect of oral exposure of rats to arsenite and/or gadolinium chloride $\left(\mathrm{GdCl}_{3}\right)$ on rat plasma total cholesterol concentration (A), rat plasma high density lipoprotein-cholesterol (HDL-C) concentration (B), rat plasma low density lipoprotein-cholesterol (LDL-C) concentration (C), and rat atherogenic index (AI - LDL/ HDL ratio) (D). Data are presented as mean value \pm SEM, $n=6$. $\alpha$ is significant at $p<0.001$ relative to arsenic only.
Several studies have implicated arsenic for lipid peroxidation, oxidative stress as well as liver damage (Zaki et al. 2011; Chandranayagam et al. 2013). Arsenic's reactivity toward sulfhydryl groups may affect several cellular functions. Studies have demonstrated that arsenite has affinity for thiol groups and could cause damage by promoting generation of reactive species (Shiobara et al. 2001; Rana et al. 2011).

The increased level of MPO and NO, consequent of arsenite intoxication may also have aided the lipid peroxidation as well as resultant oxidative cellular damage. Elevated production of NO can react with metals, reduced thiols, molecular oxygen and superoxide leading to adverse reactions (Bryan et al. 2005; Gladwin et al. 2005) leading to cellular damage (Adeyemi and Sulaiman 2014). Likewise, increased activity of MPO has been linked to oxidative cellular damage (Adeyemi and Akanji 2011b). MPO plays vital role in neutrophilic inflammation (Vita et al. 2004), and has been shown to potentiate atherosclerosis (Hazen et al. 2004). In like manner, the present study showed that arsenite exposure has capacity to predispose rats to cardiovascular disorder by increasing plasma total CHOL, LDL-C, while lowering the $\mathrm{HDL}-\mathrm{C}$ levels which raised the atherogenic index. Elevated atherogenic index has been associated with the development of atherosclerosis (Olukanni et al. 2013; Adeyemi and Orekoya 2014). Our findings agree with studies that have linked arsenic toxicity to cardiovascular disorders (Straub et al. 2008; Das et al. 2012; Kumar et al. 2014).

Furthermore, the histopathological assessment of rat liver sections showed cellular lesion caused by arsenite exposure. This supports the biochemical evaluations. Arsenic intoxication has been shown to cause hepatic fibrosis and other degenerating cellular lesions (Datta et al. 2007; Rana et al. 2011; Zaki et al. 2011; Abnosi and Jafaru 2012) similar to the observation in the present study.

However, the pre-treatment of rats with $\mathrm{GdCl}_{3}$ to inhibit the Kupffer cell functions before arsenite exposure suppressed and protected against arsenite intoxication by improving the liver function indices, the oxidative status, lipid profile and ultimately the cellular architecture. The Kupffer cells play central role in the hepatic response to toxicants or carcinogens. The activation of Kupffer cells either directly or indirectly promotes the release of inflammatory mediators as well as reactive oxygen species (ROS) which help modulate hepatic injury. In this study, the inhibition of Kupffer cell functions by $\mathrm{GdCl}_{3}$ may have reduced the production of inflammatory mediators including NO and MPO thereby protecting against cellular inflammation and damage. NO and MPO under certain conditions are pro-inflammatory and the duo have been implicated for cellular damage (Adeyemi and Sulaiman 2014). This suggests that Kupffer cells are a target for arsenic toxicity. The arsenic exposure may have activated the Kupffer cells for protective response that develops to cause cellular damage with further stimulation. 

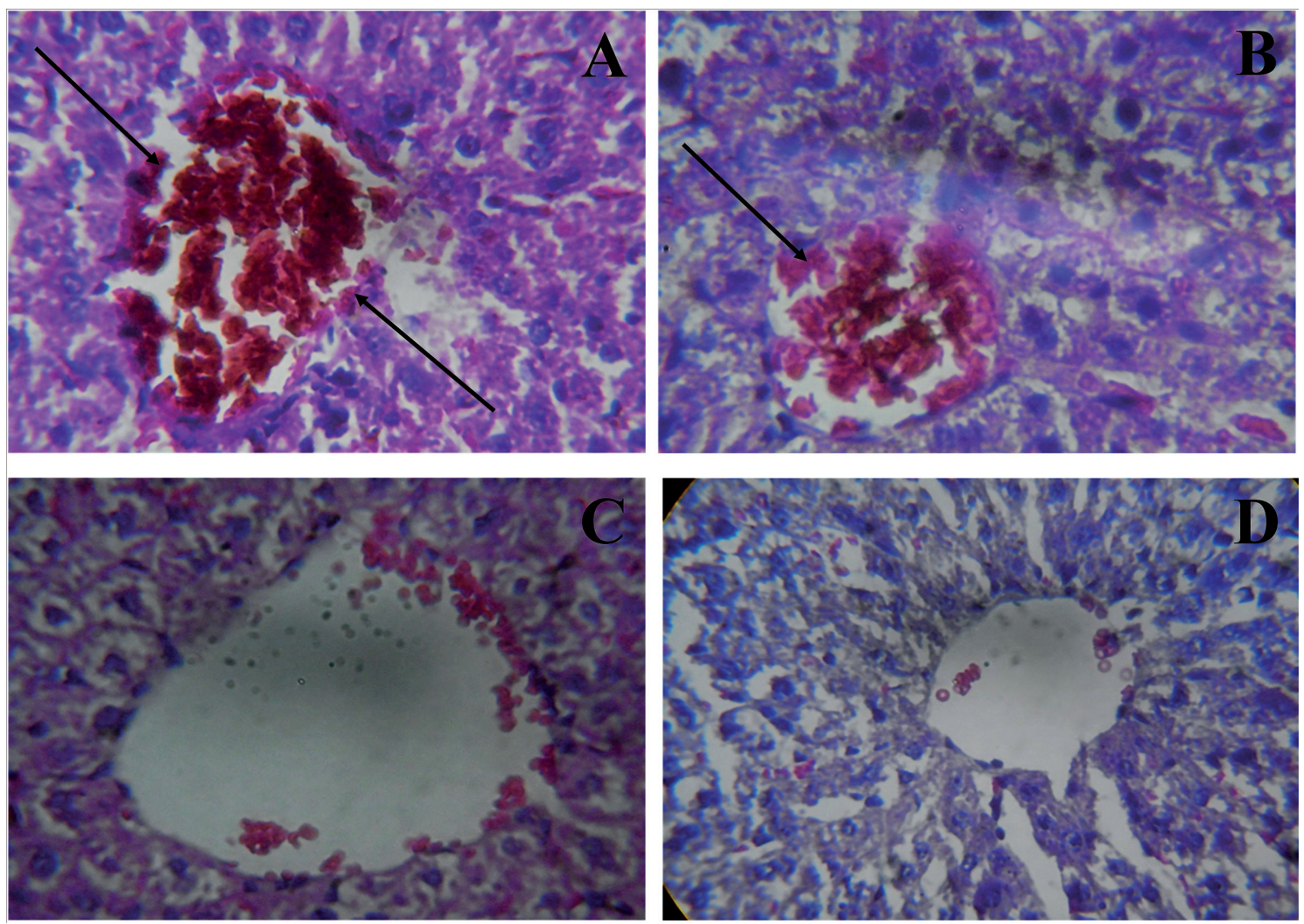

Figure 7. Photomicrographs of rat liver following exposure to arsenic and/or gadolinium chloride $\left(\mathrm{GdCl}_{3}\right)$. A. Arsenic treatment only - arrows showing distortion of the cellular architecture with a severe congestion of the central vein. B. Arsenic and gadolinium chloride treatment - arrows showing a slight distortion of the cellular architecture with a mild congestion of the central vein. C. Gadolinium chloride treatment only - showing a well preserved cellular morphology with a free central vein. D. Normal saline - showing a well preserved cellular architecture with a free central vein. H\&E Stain $(\times 400)$.

This is plausible considering that the inhibition of Kupffer cell functions by $\mathrm{GdCl}_{3}$ significantly reduced and improved the indices of arsenite intoxication. Findings in the present study revealed consistence with Roberts et al (2007) which reported that $\mathrm{GdCl}_{3}$ inhibition of Kupffer cells could mitigate chemical intoxication as well as resultant cellular damage.

\section{Conclusion}

Although Kupffer cells have dual role in the hepatic response to chemical toxicity, our data supports the complicity of Kupffer cells in arsenite intoxication. To our knowledge, this is the first study showing evidence that inhibiting Kupffer cell functions by using $\mathrm{GdCl}_{3}$ offered protection against arsenite intoxication in rats. Data would contribute to our understanding of the mechanism of arsenite intoxication.

Acknowledgements. Authors acknowledge the laboratory staff at the Department of Biological Sciences for technical support.
Conflict of interest. Authors declare that there is no conflict of interest.

\section{References}

Abnosi M. H., Jafari Y. Z. (2012): Low dose and long term toxicity of sodium arsenite caused caspase dependent apoptosis based on morphology and biochemical character. Cell J. 14, 161-170

Adeyemi O. S., Akanji M. A. (2011a): Biochemical changes in the kidney and liver of rats following administration of ethanolic extract of Psidium guajava leaves. Hum. Exp. Toxicol. 30, 1266-1274

https://doi.org/10.1177/0960327110388534

Adeyemi O. S., Akanji M. A. (2011b): Iron and nitric oxide play key roles in the development of cardiovascular disorder. J. Toxicol. Environ. Health Sci. 3, 249-253

Adeyemi O. S., Fambegbe M., Daniyan O. R., Nwajei I. (2012): Yoyo Bitters, a polyherbal formulation influenced some biochemical parameters in Wistar rats. J. Basic Clin. Physiol. Pharmacol. 23, $135-138$

https://doi.org/10.1515/jbcpp-2012-0026 
Adeyemi O. S., Orekoya B. (2014): Lipid profile and oxidative stress markers in rats following oral and repeated exposure to Fijk herbal mixture. J. Toxicol. 2014, 876035 https://doi.org/10.1155/2014/876035

Adeyemi O. S., Sulaiman F. A. (2012): Biochemical and morphological changes in Trypanosoma brucei brucei- infected rats treated with homidium chloride and diminazene aceturate. J. Basic. Clin. Physiol. Pharmacol. 23, 179-183 https://doi.org/10.1515/jbcpp-2012-0018

Adeyemi O. S., Sulaiman F. A. (2014): Co-administration of iron sulphate and nitroglycerin promoted oxidative stress and mild tissue damage in Wistar rats. Comp. Clin. Pathol. 23, 1525-1533 https://doi.org/10.1007/s00580-013-1817-2

Akanji M. A., Adeyemi O. S., Oguntoye S. O., Sulyman F. (2009): Psidium guajava extract reduces trypanosomosis associated lipid peroxidation and raises glutathione concentrations in infected animals. EXCLI Journal 8, 148-154

Aliyu M., Odunola O. A., Owumi S. E., Habila N., Aimola I. A., Eukainure O. L. (2012): Ethanol suppresses the effects of sodium arsenite in male Wister albino rats. Sci. Reports 1, 222 doi:10.4172/scientificreports.222 https://doi.org/10.4172/scientificreports.222

Bryan N. S., Fernandez B. O., Bauer S. M., Garcia-Saura M. F., Milsom A. B., Rassaf T., Maloney R. E., Bharti A., Rodriquez J., Feelisch M. (2005): Nitrite is a signaling molecule and regulator of gene expression in mammalian tissues. Nat. Chem. Biol. 1, 290-297 https://doi.org/10.1038/nchembio734

Chandranayagam C., Veeraraghavan G., Subash A., Vasanthi H. R. (2013): Restoration of arsenite induced hepato-toxicity by crude tannin rich fraction of Theobroma cacao in Sprague Dawley rats. Food Res. Int. 50, 46-54 https://doi.org/10.1016/j.foodres.2012.09.021

Chowdhury M. A. I., Uddin M. T., Ahmed M. F., Ali M. A., Uddin S. M. (2006): How does arsenic contamination of groundwater cause severity and health hazard in Bangladesh. J. Appl. Sci. 6, 1275-1286 https://doi.org/10.3923/jas.2006.1275.1286

Das N., Paul S., Chatterjee D., Banerjee N., Majumder N. S., Sau T. J., Basu S., Banerjee S., Majumder P., Bandyopadhyay A. K., States J. C., Giri A. K. (2012): Arsenic exposure through drinking water increases the risk of liver and cardiovascular diseases in the population of West Bengal, India. BMC Public Health. 12, 639 https://doi.org/10.1186/1471-2458-12-639

Datta S., Saha D. R., Ghosh R., Majumdar T., Bhattacharya S., Mazumder S. (2007): Sublethal concentration of arsenic interferes with the proliferation of hepatocytes and induces in vivo apoptosis in Clarias batrachus L. Comp. Biochem. Physiol. part C: Toxicol. Pharmacol. 145, 339-349

Ding H., Peng R., Reed E., Li Q. Q. (2003): Effects of Kupffer cell inhibition on liver function and hepatocellular activity in mice. Int. J. Mol. Med. 12, 549-557

https://doi.org/10.3892/ijmm.12.4.549

Eiserich J. P., Hristova M., Cross C. E. (1998): Formation of nitric oxide-derived inflammatory oxidants by myeloperoxidase in neutrophils. Nature 391, 393-397 https://doi.org/10.1038/34923
Ekanem J. T., Johnson T. O., Balogun E. A. (2009): Serum Iron and nitric oxide production in Trypanosoma brucei infected rats treated with tetracycline. Biokemistri 21, 41-51

Ellman G. I. (1959): Tissue sulfhydryl groups. Arch. Biochem. Biophys. 82, 70-77 https://doi.org/10.1016/0003-9861(59)90090-6

Gbadegesin M. A., Odunola O. A. (2010): Aqueous and ethanolic leaf extracts of Ocimum basilicum (sweet basil) protect against sodium arsenite-induced hepatotoxicity in Wistar rats. Nig. J. Physiol. Sci. 25, 29-36

Gladwin M. T., Schechter A. N., Kim-Shapiro D. B., Patel R. P., Hogg N., Shiva S., et al. (2005): The emerging biology of the nitrite anion. Nature Chem. Biol. 1, 308-314 https://doi.org/10.1038/nchembio1105-308

Hazen S. L. (2004): Myeloperoxidase and plaque vulnerability. Arterioscler. Thromb. Vasc. Biol. 24, 1143-1146 https://doi.org/10.1161/01.ATV.0000135267.82813.52

Hughes M. F., Beck B. D., Chen Y., Lewis A. S., Thomas D. J. (2011): Arsenic exposure and toxicology: a historical perspective. Toxicol. Sci. 123, 305332 https://doi.org/10.1093/toxsci/kfr184

Ito Y., Bethea N. W., Abril E. R., McCuskey R. S. (2003): Early hepatic microvascular injury in response to acetaminophen toxicity. Microcirculation 10, 391-400 https://doi.org/10.1038/sj.mn.7800204

Jørgensen P. F., Götzinger P., Scholz T., Gundersen Y., Sautner T., Függer R., Lilleaasen P., Aasen A. O. (2001): The role of Kupffer cell inhibition in porcine endotoxemia. Shock 16, 466-472 https://doi.org/10.1097/00024382-200116060-00011

Ju C., Reilly T. P., Bourdi M., Radonovich M. F., Brady J. N., George J. W., Pohl L. R. (2002): Protective role of Kupffer cells in acetaminopheninduced hepatic injury in mice. Chem. Res. Toxicol. 15, 1504-1513 https://doi.org/10.1021/tx0255976

Kresse M., Latta M., Kunstle G., Riehle H. M., van Rooijen N., Hentze H., Tiegs G., Biburger M., Lucas R., Wendel A. (2005): Kupffer cell expressed membrane-bound TNF mediates melphalan hepatotoxicity via activation of both TNF receptors. J. Immunol. 175, 4076-4083 https://doi.org/10.4049/jimmunol.175.6.4076

Kumar A., Suman S., Kumar R., Singh J. K., Ali M. (2014): Hepatoprotective effect of edible Oyster mushroom Pleurotuscornucopiae against Sodium Arsenite induced hepatotoxicity in rats. Int. J. Phytomed. 6, 275-279

Lowry O. H., Rosbrough N. J., Farr A. L., Randall R. J. (1951): Protein measurement with the Folin phenol reagent. J. Biol. Chem. 193, 265-275

Mishra D., Mehta A., Flora S. J. S. (2008): Reversal of arsenic induced hepatic apoptosis with combined administration DMSA and its analogue in Guinea pigs: Role of glutathione and linked enzymes. Chem. Res. Toxicol. 21, 400-407 https://doi.org/10.1021/tx700315a

Morakinyo A. O., Achema P. U., Adegoke O. (2010): Effect of zingiber officinale (Ginger) on sodium arsenite induced reproductive toxicity in male rats. Afr. J. Biomed. Res. 13, 39-45

National Research Council (2011): Guide for the Care and Use of Laboratory Animals. (8th Edition), pp. 161-169, National Academies Science Press 
Niehaus W. G., Samuelson B. (1968): Formation of malondialdehyde from phospholipid arachidonate during microsomal lipid peroxidation. Eur. J. Biochem. 6, 126-130 https://doi.org/10.1111/j.1432-1033.1968.tb00428.x

Okoji R. S., Yu R. C., Maronpot R. R., Froines J. R. (2002): Sodium arsenite administration via drinking water increases genomewide and Ha-ras DNA hypomethylation in methyl-deficient C57BL/6J mice. Carcinogenesis 23, 777-785 https://doi.org/10.1093/carcin/23.5.777

Olukanni O. D., Akande O. T., Alagbe Y. O., Adeyemi O. S., Olukanni A. T., Daramola G. G. (2013): Lemon juice elevated level of reduced glutathione and improved lipid profile in Wistar rats. American-Eurasian J. Agric. \& Environ. Sci. 13, $1246-1251$

Prins H. A., Meijer C., Boelens P. G., Diks J., Holtz R., Masson S., Daveau M., Meijer S., Scotte M., van Leeuwen P. A. (2004): Kupffer cell-depleted rats have a diminished acute-phase response following major liver resection. Shock 21, 561-565 https://doi.org/10.1097/01.shk.0000126649.96850.36

Rana T., Bera A. K., Das S., Bhattacharya D., Pan D., Bandyopadhyay S., De S., Das S. K. (2011): Mushroom lectin protects arsenic induced apoptosis in hepatocytes of rodents. Hum. Exp. Toxicol. 30, 307-317. https://doi.org/10.1177/0960327110372642

Roberts R. A., Ganey P. E., Ju C., Kamendulis L. M., Rusyn I., Klaunig J. E. (2007): Role of the Kupffer Cell in Mediating Hepatic Toxicity and Carcinogenesis. Toxicol. Sci. 96, 2-15 https://doi.org/10.1093/toxsci/kfl173

Shiobara Y., Ogra Y., Suzuki K. T. (2001): Animal species difference in the uptake of dimethylarsinous acid (dma(iii)) by red blood cells. Chem. Res. Toxicol. 14, 1446-1452 https://doi.org/10.1021/tx015537k

Straub A. C., Clark K. A., Ross M. A., Chandra A. G., Li S., Gao X., Pagano P. J., Stolz D. B., Barchowsky A. (2008): Arsenicstimulated liver sinusoidal capillarization in mice requires NADPH oxidase-generated superoxide. J. Clin. Invest. 118, 3989 https://doi.org/10.1172/JCI35092
Sulaiman F. A., Ahmed El-Imam A. M., Adeyemo A. A., Muhammed R. B., Sulaiman A. M., Aliyu A. O., Adeyemi O. S. (2015): Aspergillus niger-fermented Jatropha curcas seed cake: proximate composition and effects on biochemical indices in Wistar rats. Biological Lett. 51, 37-46

Swaran F. J. S., Smrati Bhadauria T., Satish C. P., Ram K. D. (2005): Arsenic induced blood and brain oxidative stress and its response to some thiol chelators in rats. Life Sci. 77, 2324-2337 https://doi.org/10.1016/j.lfs.2005.04.016

Vita J. A., Brennan M. L., Gokce N., Mann S. A., Goormastic. M., Shishehbor M. H., Penn M. S., Keaney J. F. Jr, Hazen S. L. (2004): Serum myeloperoxidase levels independently predict endothelial dysfunction in humans. Circulation 110, 1134-1139 https://doi.org/10.1161/01.CIR.0000140262.20831.8F

Warnick G. R., Knopp R. H., Fitzpatrick V., Branson L. (1990): Estimating low-density lipoprotein cholesterol by the Friedewald equaton is adequate for classifying patients on the basis of nationally recommended cutpoints. Clin. Chem. 36, 15-19

Yao H. W., Li J., Chen J. Q., Xu S. Y. (2004): A 771726, the active metabolite of leflunomide, inhibits TNF-alpha and IL-1 from Kupffer cells. Inflammation 28, 97-103 https://doi.org/10.1023/B:IFLA.0000033025.73363.d3

Yee S. B., Kinser S., Hill D. A., Barton C. C., Hotchkiss J. A., Harkema J. R., Ganey P. E., Roth R. A. (2000): Synergistic hepatotoxicity from coexposure to bacterial endotoxin and the pyrrolizidine alkaloid monocrotaline. Toxicol. Appl. Pharmacol. 166, 173-185 https://doi.org/10.1006/taap.2000.8968

Zaki N. I., El-halwagy M. E. A., Darwish S. K., Mohammed A. S. (2011): Impacts of paracetamol, malathion and arsenic or their combinations on liver and pancreas of albino rats. Aust. J. Basic Appl. Sci. 5, 473-481.

Received: January 9, 2016

Final version accepted: September 6, 2016

First published online: February 2, 2017 